\title{
Annecy-le-Vieux - Les Illettes nord, avenue de Genève
}

Opération préventive de diagnostic (2013)

\section{Christophe Landry}

\section{(2) OpenEdition \\ Journals}

Édition électronique

URL : https://journals.openedition.org/adlfi/14883

ISSN : 2114-0502

\section{Éditeur}

Ministère de la Culture

\section{Référence électronique}

Christophe Landry, «Annecy-le-Vieux - Les Illettes nord, avenue de Genève » [notice archéologique], ADLFI. Archéologie de la France - Informations [En ligne], Auvergne-Rhône-Alpes, mis en ligne le 28 mai 2015, consulté le 29 juillet 2021. URL : http://journals.openedition.org/adlfi/14883

Ce document a été généré automatiquement le 29 juillet 2021.

(c) ministère de la Culture et de la Communication, CNRS 


\section{Annecy-le-Vieux - Les Illettes nord, avenue de Genève}

Opération préventive de diagnostic (2013)

\section{Christophe Landry}

\section{NOTE DE L'ÉDITEUR}

Organisme porteur de l'opération : Inrap

1 L'emprise diagnostiquée du 25 juin au 3 juillet 2013, en préalable à la construction d'un ensemble immobilier de 309 logements, s'avère exempte de tout indice d'occupation archéologique antérieure à l'époque moderne. 35 sondages ont pu être réalisés sur les $43942 \mathrm{~m}^{2}$ concernés par le projet. L'emprise est localisée sur deux niveaux de terrasses inscrites en rive gauche convexe du Fier, à la base du versant occidental d'une butte molassique, juste à l'aval du seuil de Brogny. Le haut niveau s'étend entre 458 et $452 \mathrm{~m}$, alors que le niveau inférieur, plus subhorizontal, s'étend de 443 à $437 \mathrm{~m}$. L'expertise géomorphologique conduite sur documents graphiques et photographiques permet de définir deux unités morphologiques :

- la haute terrasse semble d'origine fluvio-glaciaire et les chenaux ont incisé localement les bancs molassiques. Après le retrait du lit du Fier (incision postglaciaire), le secteur semble avoir enregistré uniquement des dépôts de pentes depuis le versant de la butte molassique dominante : ruissellement aréolaire et écoulement boueux pouvant entraîner localement des blocs centimétriques. La présence d'artefacts antiques dans les dépôts supérieurs permet de distinguer une séquence historique dans cet exhaussement colluvial.

- la basse terrasse présente une formation graveleuse alluviale, probablement d'âge holocène, à revêtement sablo-limoneux de débordement à courants lents, démontrant l'encaissement $\mathrm{du}$ lit du Fier qui s'écoule aujourd'hui à un niveau moyen de $433 \mathrm{~m}$ d'altitude au droit de l'emprise. Le relief de la surface actuelle de ces terrains bas résulte de l'apport au cours des trente dernières années d'importants remblais pouvant atteindre par endroits $6,50 \mathrm{~m}$ d'épaisseur. 
2 L'exploration des parcelles bordant l'actuelle avenue de Genève permet de conclure à l'absence de toute preuve accréditant l'hypothèse traditionnelle concernant le tracé de la voie antique reliant Boutae à Genava par le pont de Brogny. Les observations réalisées sur l'ancien pont ainsi qu'une recherche documentaire sommaire démontrent que l'état actuel de l'ouvrage correspond aux réfections de 1659, sa construction datant de 1578. Le pont a subi récemment de sérieuses détériorations : démolition de la culée en rive droite lors de travaux, chutes de blocs du parapet, effondrement partiel de la culée gauche. La restauration de l'ouvrage et le réaménagement de ses abords en rive gauche s'avèrent urgents, et seraient l'occasion de rechercher des traces éventuelles d'un ouvrage antérieur et de l'hypothétique voie romaine.

Le projet ayant donné lieu à la prescription concerne également la réhabilitation partielle du site de la minoterie Cléchet, héritière du moulin et de la scierie fondés en 1845 sous le régime sarde. La consultation de plans anciens nous renseigne sur la nature des bâtiments et installations conservés (bureaux, magasins à farines, hangar, vanne de prise d'eau, canal d'amenée et centrale hydroélectrique), et des éléments démolis cette année (moulin, graineterie, silos à blé, garages, "grinnel»). Les plans permettent également de localiser les conduites forcées enterrées qui nous ont contraints à ne pas sonder la majeure partie de la cour de l'usine.

Enfin, le bâtiment abandonné situé en bordure de l'avenue de Genève, et destiné à être converti en HLM, a fait l'objet d'une étude sommaire. Il s'agit d'une ferme construite à

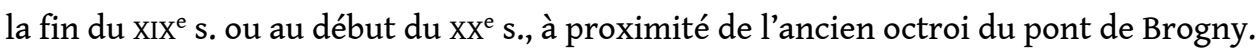

L'édifice a subi une extension vers le nord de l'étable et de la grange. Les mangeoires, box et boiseries sont encore en place et en bon état, mais aucun élément antique en remploi n'est actuellement apparent. Seule une borne matérialisant autrefois l'octroi a été déplacée et se trouve au pied du mur qui clôture le jardin attenant à la ferme.

\section{INDEX}

lieux https://ark.frantiq.fr/ark:/26678/pcrtSEeAipsBlD, https://ark.frantiq.fr/ark:/26678/ crtB8WDyqd6u9, https://ark.frantiq.fr/ark:/26678/pcrt5V2VjpTJWV, https://ark.frantiq.fr/ark:/ 26678/pcrt1qNjFdpyFN, https://ark.frantiq.fr/ark:/26678/pcrtNzBvpPsolP

nature https://ark.frantiq.fr/ark:/26678/pcrtWWQS75V5Bc

chronologie https://ark.frantiq.fr/ark:/26678/pcrtPSEEZSBEJp, https://ark.frantiq.fr/ark:/

26678/pcrt59R77d1H15

Année de l'opération : 2013

sujets https://ark.frantiq.fr/ark:/26678/pcrtjclbYvph1S, https://ark.frantiq.fr/ark:/26678/

pcrttcSF6qn4l3 
AUTEURS

CHRISTOPHE LANDRY

Inrap 